\title{
Postoperative myocardial infarction in acute type A aortic dissection: A report from the International Registry of Acute Aortic Dissection
}

\author{
Stephen D. Waterford, MD, MS, ${ }^{a}$ Marco Di Eusanio, MD, PhD, ${ }^{\mathrm{b}}$ Marek P. Ehrlich, MD, \\ T. Brett Reece, MD, ${ }^{\mathrm{d}}$ Nimesh D. Desai, MD, PhD, ${ }^{\mathrm{e}}$ Thoralf M. Sundt, MD, ${ }^{\mathrm{f}}$ Truls Myrmel, MD, ${ }^{\mathrm{g}}$ \\ Thomas G. Gleason, MD, ${ }^{\mathrm{h}}$ Alberto Forteza, MD, ${ }^{\mathrm{i}}$ Carlo de Vincentiis, MD, ${ }^{\mathrm{j}}$ Anthony W. DiScipio, MD, ${ }^{k}$ \\ Daniel G. Montgomery, MS, Kim A. Eagle, MD, ${ }^{1}$ Eric M. Isselbacher, MD ${ }^{\mathrm{m}}$ Anja Muehle, MD, ${ }^{\mathrm{n}}$ \\ Aamir Shah, MD, ${ }^{a}$ Daisy Chou, MD, ${ }^{a}$ Christoph A. Nienaber, MD, PhD, ${ }^{\circ}$ and Ali Khoynezhad, MD, PhD
}

\begin{abstract}
Objective: Postoperative myocardial infarction remains a serious complication in cardiac surgery. The incidence and impact of this condition in acute type A aortic dissection are poorly understood.

Methods: A total of 1445 patients with acute type A aortic dissection who underwent surgery were enrolled in the International Registry of Acute Aortic Dissection from 1996 to 2013. Individuals with preoperative myocardial infarction at hospital presentation and a history of myocardial infarction were excluded. Patients with postoperative myocardial infarction $(n=38,2.6 \%)$ were compared with those without postoperative myocardial infarction $(n=1407,97.4 \%)$.
\end{abstract}

Results: The postoperative myocardial infarction group was more often of white race $(100 \%$ vs $90 \%, P=.043)$ with bicuspid aortic valve $(15.6 \%$ vs $4.5 \%$, $P=.015)$. Imaging demonstrated more aortic root involvement $(75.8 \%$ vs $49.5 \%, P=.003)$, pericardial effusion $(65.5 \%$ vs $44.1 \%, P=.022)$, and coronary artery compromise $(27.3 \%$ vs $10.2 \%, P=.022)$. Patients with postoperative myocardial infarction were more frequently hypotensive or in shock during surgery $(42.9 \%$ vs $25.5 \%, P=.021)$. Patients with postoperative myocardial infarction were more likely to have undergone root replacement $(54.5 \%$ vs $33.3 \%, P=.011)$, coronary artery bypass grafting $(28.6 \%$ vs $7.4 \%, P<.001)$, or aortic valve replacement $(40.0 \%$ vs $23.8 \%, P=.027)$, and less likely to have had complete arch replacement $(2.8 \%$ vs $14.0 \%, P=.050)$. Median circulatory arrest time was higher in postoperative myocardial infarction (60 vs 38 minutes, $P=.024)$. In-hospital mortality $(57.9 \%$ vs $16.3 \%, P<.001)$ and Kaplan-Meier estimates of 5-year mortality $(P=.007)$ were distinctly higher in postoperative myocardial infarction.

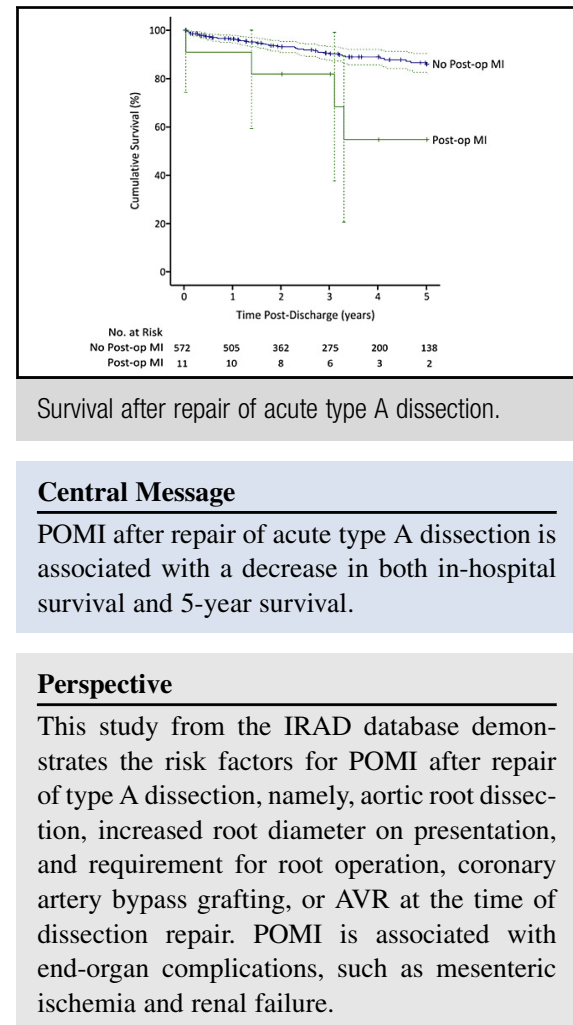

See Editorial Commentary page 528.

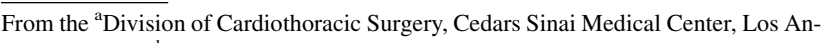
geles, Calif; ' ${ }^{\mathrm{D}}$ Department of Cardiac Surgery, University of Bologna, Bologna, Italy; ' Department of Cardiothoracic Surgery, University of Vienna, Vienna, Austria; ${ }^{\mathrm{d} D i v i s i o n}$ of Cardiothoracic Surgery, University of Colorado, Aurora, Colo; ${ }^{e}$ Division of Cardiothoracic Surgery, University of Pennsylvania, Philadelphia, Pa; ${ }^{\mathrm{f}}$ Division of Cardiothoracic Surgery, Massachusetts General Hospital, Boston, Mass; ${ }^{g}$ Department of Thoracic and Cardiovascular Surgery, University of Tromsoe, Tromsoe, Norway; ${ }^{\mathrm{h}}$ Department of Cardiothoracic Surgery, University

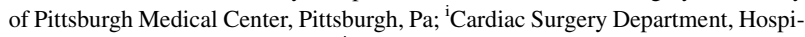
tal Quiron Madrid, Madrid, Spain; ${ }^{j}$ Department of Cardiac Surgery, Policlinico San Donato, San Donato Milanese, Italy; ${ }^{\mathrm{k}}$ Division of Surgery, Dartmouth Hitchcock Medical Center, Lebanon, NH; ${ }^{1}$ Cardiovascular Division, University of Michigan, Ann Arbor, Mich; ${ }^{\mathrm{m}}$ Cardiology Division, Massachusetts General Hospital, Boston, Mass; ${ }^{\mathrm{n}}$ Department of Cardiac Surgery, Heart Center Leipzig, Leipzig, Germany; and ${ }^{\circ}$ Cardiology and Aortic Center, Royal Brompton Hospital, London, United Kingdom.
}

Funded by an internal grant by the Khoynezhad Laboratory, Department of Surgery, Cedars-Sinai Medical Center. The International Registry of Acute Aortic Dissection Registry is funded through grants provided by WL Gore and Associates, Inc, Medtronic, the Varbedian Aortic Research Fund, the Hewlett Foundation, the Mardigian Foundation, University of Michigan Faculty Group Practice, Terumo, and Ann and Bob Aikens.

Received for publication Oct 18, 2015; revisions received Oct 13, 2016; accepted for publication Oct 20, 2016; available ahead of print Dec 6, 2016.

Address for reprints: Ali Khoynezhad, MD, PhD, Division of Cardiothoracic Surgery, Cedars-Sinai Medical Center, 127 S. San Vicente Blvd, Suite A3306, Los Angeles, CA 90048 (E-mail: Akhoy@ cshs.org).

0022-5223/\$36.00

Copyright (C) 2016 by The American Association for Thoracic Surgery

http://dx.doi.org/10.1016/j.jtcvs.2016.10.064 


\section{Abbreviations and Acronyms \\ $\mathrm{EKG}=$ electrocardiogram \\ IRAD $=$ International Registry of Acute Aortic Dissection \\ MI = myocardial infarction \\ $\mathrm{POMI}=$ postoperative myocardial infarction}

Scanning this QR code will take you to the article title page.

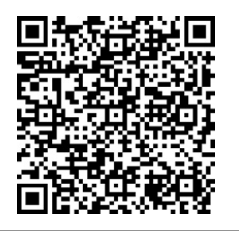

Conclusions: Postoperative myocardial infarction is a devastating complication of type A aortic dissection repair. It is associated with bicuspid aortic valve, root involvement, pericardial effusion, and extent of surgical repair. Patients with postoperative myocardial infarction have higher serious postoperative complications, in-hospital mortality, and 5year mortality rates than those without postoperative myocardial infarction. (J Thorac Cardiovasc Surg 2017;153:521-7)

Acute type A aortic dissection is a catastrophe, and medical management is associated with high mortality. ${ }^{1,2}$ Urgent surgical management is indicated in patients with type A dissection. It is well known that myocardial infarction (MI) can be a presenting feature of type A dissection. However, postoperative myocardial infarction (POMI), defined as a new-onset MI after operative intervention for type A dissection (no MI on presentation), is poorly understood. Numerous trials have demonstrated that elevation of cardiac enzymes after cardiac surgery is predictive of mortality, although the risk factors for such elevation have remained poorly defined. ${ }^{3,4}$ POMI has been best studied after coronary artery bypass grafting operations, and risk factors include preoperative intra-aortic balloon pump, cardiopulmonary bypass time, number of distal anastomoses, and on-pump versus off-pump approach. ${ }^{5,6}$ However, which patients with a type A dissection are at risk for POMI and the impact of POMI on morbidity and mortality of type A dissection have not been well delineated. We analyzed data from the International Registry of Acute Aortic Dissection (IRAD) to define the incidence, risk factors, and impact of POMI on mortality and survival of type A dissection.

\section{MATERIALS AND METHODS \\ Registry Design}

The IRAD is composed of 40 high-volume aortic centers in 11 countries, collecting comprehensive data on the presentation and treatment of patients with aortic dissection. Participating centers report consecutive cases of acute dissection to the IRAD Coordinating Center at the University of Michigan, which performs internal checks for validity. The institutional review boards at each center have approved data collection. Further details of the registry have been published. ${ }^{2}$

\section{Study Design}

Patients presenting with acute type A aortic dissection to an IRAD center who underwent operative management of a noniatrogenic type A aortic dissection formed the study cohort. Those with new POMI were compared with those without POMI. Exclusion criteria for this study were iatrogenic type A dissection and preoperative MI whether old or new, defined by old or new Q waves, new ST elevation, or elevated levels of biomarkers for MI. Patients with old MI were excluded from analysis because of the presence of a past MI as a potential confounder in the analysis. Patients who did not have preoperative electrocardiogram (EKG) information available were excluded, adding to the total number of excluded patients. A flowchart of patients included in this study is provided in Figure 1.

POMI was diagnosed with EKG, echocardiographic, or laboratory abnormalities. Patients who had POMI were found to have new $\mathrm{Q}$ waves that are 0.03 seconds in width, one third or more of the QRS complex in 2 or more contiguous leads, or ST elevation more than $1.0 \mathrm{~mm}$ in earlyphase or new Q-wave or new left bundle branch block. Echocardiographic definition was any new persistent wall motion abnormality or evidence of complications of MI, such as myocardial free wall rupture, acute ventricular septal defect, and mitral regurgitation secondary to papillary muscle rupture or ischemia. Laboratory diagnosis was made with creatine kinase-MB 5 times or more the upper limit of normal, or cardiac troponin values 10 times higher than $99 \%$ of the upper reference limit.

The primary outcome measure was in-hospital mortality. Secondary outcome measures included early morbidity and 5-year survival. Furthermore, univariate and multivariate risk factors for POMI were ascertained.

\section{Patient Selection}

From January 1996 to October 2013, a total of 2953 acute type A dissections were entered into the IRAD database, and of these, 1445 patients $(48.9 \%)$ presented with acute type A aortic dissection and met the entry criteria for this analysis. Type A dissection was defined according to the Stanford classification. ${ }^{7}$ A total of 38 of these patients had POMI, and 1407 patients did not have POMI.

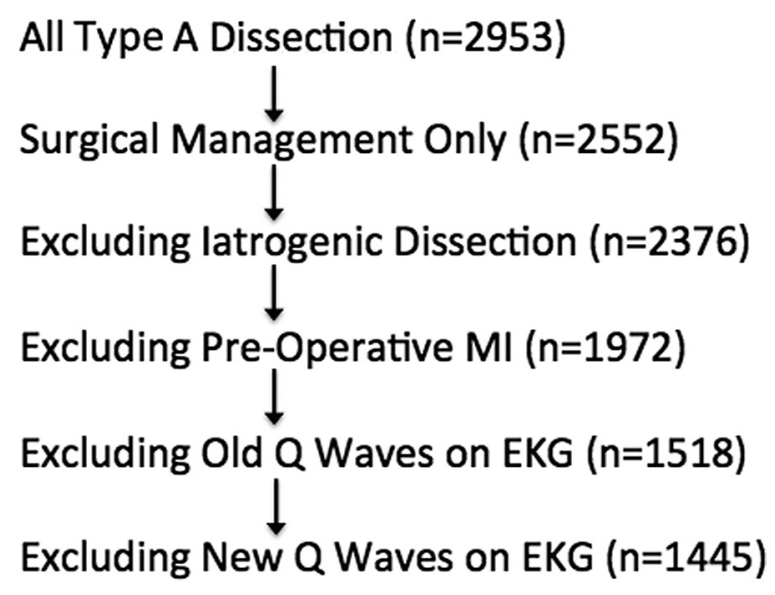

FIGURE 1. Flowchart of patients included for analysis. MI, Myocardial infarction; $E K G$, electrocardiogram. 


\section{Data Collection}

Forms for individual patients were completed by the treating surgeon. Hemodynamics at surgery refer to the beginning of the operation and were completed by the operating surgeon, allowing the surgeon to note whether the patient was hypotensive at the time of operation. Operation types may overlap. For instance, patients listed as having aortic valve replacement also can be listed as having undergone root replacement, should this have been required.

\section{Variable Definitions}

Hypotension/shock at the time of surgery is defined in the IRAD database as follows: systolic blood pressure less than $90 \mathrm{~mm} \mathrm{Hg}$; use of intravenous inotropes, vasoactive medications, or mechanical support; cardiac index less than $1.8 \mathrm{~L} / \mathrm{min} / \mathrm{m}^{2}$; and patient in a state of compensated shock as evidence by decreased peripheral pulses, decreased capillary refill and cool skin temperature, or $\mathrm{pH}$ less than 7.2 or lactate greater than $4 \mathrm{mmol} / \mathrm{L}$. Hypotension in the postoperative period is defined in the IRAD intake form as indicating whether the systolic blood pressure decreased to less than $90 \mathrm{~mm} \mathrm{Hg}$ from an earlier higher recording.

Coronary artery compromise is defined in the IRAD database as proximal coronary narrowing as a result of dissection, due to occlusion of the ostia by the intimal flap, regardless of the type of imaging modality used.

Prior aortic dissection is defined as any history of an aortic dissection regardless of type or management. This encompasses patients with medically managed type B dissections, but also includes patients who underwent intervention for any type of dissection. Patients who specifically underwent surgery for an aneurysm or dissection are separately identified in the IRAD database.

\section{Statistical Analysis}

Univariate analysis compared patients with surgically managed type A aortic dissection with and without POMI. Categoric variables were compared using chi-square analysis or Fisher exact test where appropriate. Continuous variables were analyzed with 2-sample $t$ tests or Wilcoxon rank-sum tests. Variables with $P$ less than .20 in the univariate analysis were subsequently entered in the multivariate analysis, described next. All variables were checked for proportionality with standard plots of cumulative hazard versus time and $\log$ minus log versus time. Multiple logistic regression analysis was performed to create an in-hospital mortality model and evaluate independent risk factors. A Cox proportional hazards regression analysis was performed to create a 5-year mortality model. Kaplan-Meier analysis generated 5-year survival curves, and the log-rank test was used to compare survival between groups. All statistics were performed with SPSS version 20 (IBM Corporation, Armonk, NY).

\section{RESULTS}

A total of 2953 patients with acute type A dissection were identified, and $51 \%$ were excluded for iatrogenic

TABLE 1. Variables associated with postoperative myocardial infarction

\begin{tabular}{|c|c|c|c|}
\hline Variable & $\begin{array}{l}\text { Frequency of POMI when variable } \\
\text { in first column present }\end{array}$ & $\begin{array}{c}\text { Frequency of POMI when variable } \\
\text { in first column absent }\end{array}$ & $P$ value \\
\hline History of hypertension & $27 / 1028(2.6 \%)$ & $11 / 417(2.6 \%)$ & .698 \\
\hline Diabetes & $4 / 87(4.6 \%)$ & $34 / 1358(2.5 \%)$ & .289 \\
\hline Marfan syndrome & $2 / 63(3.2 \%)$ & $36 / 1382(2.6 \%)$ & .678 \\
\hline Atherosclerosis & $10 / 261(3.8 \%)$ & $28 / 1184(2.4 \%)$ & .207 \\
\hline Prior aortic dissection & $0 / 42(0.0 \%)$ & $38 / 1403(2.7 \%)$ & .626 \\
\hline Bicuspid aortic valve & $5 / 60(8.3 \%)$ & $33 / 1377(2.4 \%)$ & .015 \\
\hline Aortic valve disease & $4 / 160(2.5 \%)$ & $34 / 1285(2.6 \%)$ & 1.000 \\
\hline COPD & $2 / 35(5.7 \%)$ & $36 / 1410(2.5 \%)$ & .094 \\
\hline Chronic renal insufficiency & $1 / 33(3.3 \%)$ & $37 / 1411(2.6 \%)$ & .407 \\
\hline Prior cardiac surgery & $5 / 133(3.8 \%)$ & $33 / 1312(2.5 \%)$ & .407 \\
\hline Catheterization/angiography & $1 / 87(1.1 \%)$ & $37 / 1358(2.7 \%)$ & .723 \\
\hline PCI & $1 / 18(5.6 \%)$ & $37 / 1427(2.6 \%)$ & .383 \\
\hline CABG & $2 / 40(5.0 \%)$ & $36 / 1405(2.6 \%)$ & .301 \\
\hline Aortic aneurysm/dissection & $2 / 66(3.0 \%)$ & $36 / 1379(2.6 \%)$ & .703 \\
\hline AVR & $3 / 49(6.1 \%)$ & $35 / 1396(2.5 \%)$ & .147 \\
\hline MVR & $0 / 5(0.0 \%)$ & $38 / 1440(2.6 \%)$ & 1.000 \\
\hline \multicolumn{4}{|l|}{ Site of most proximal extension } \\
\hline Aortic root & $25 / 696(3.6 \%)$ & $13 / 724(1.8 \%)$ & .003 \\
\hline Sinotubular junction & 4/204 (2.0\%) & $34 / 1241(2.7 \%)$ & .808 \\
\hline Ascending aorta & $4 / 448(0.9 \%)$ & $34 / 997(3.4 \%)$ & .012 \\
\hline Arch & $0 / 24(0.0 \%)$ & $38 / 1421(2.7 \%)$ & 1.000 \\
\hline \multicolumn{4}{|l|}{ Site of intimal tear } \\
\hline Ascending & $7 / 532(1.3 \%)$ & $31 / 913(3.4 \%)$ & .039 \\
\hline Arch & $1 / 62(1.6 \%)$ & $37 / 1383(2.7 \%)$ & 1.000 \\
\hline Arch vessel involvement & $12 / 434(2.8 \%)$ & $26 / 1011(2.6 \%)$ & .381 \\
\hline Pericardial effusion & $19 / 568(3.3 \%)$ & $19 / 858(2.2 \%)$ & .022 \\
\hline Periaortic hematoma & $7 / 270(2.6 \%)$ & $31 / 1175(2.6 \%)$ & .550 \\
\hline Coronary arteries compromised & $6 / 110(5.5 \%)$ & $32 / 1335(2.4 \%)$ & .022 \\
\hline
\end{tabular}

POMI, Postoperative myocardial infarction; $C O P D$, chronic obstructive pulmonary disease; $P C I$, percutaneous coronary intervention; $C A B G$, coronary artery bypass grafting; $A V R$, aortic valve replacement; $M V R$, mitral valve replacement. 
TABLE 2. Continuous variables associated with postoperative myocardial infarction

\begin{tabular}{lccc}
\hline \multicolumn{1}{c}{ Variable } & $\begin{array}{c}\text { POMI } \\
(\mathbf{n = 3 8})\end{array}$ & $\begin{array}{c}\text { No POMI } \\
(\mathbf{n = 1 4 0 7 )}\end{array}$ & $\begin{array}{c}\boldsymbol{P} \\
\text { value }\end{array}$ \\
\hline Age, y & $59.7 \pm 15.3$ & $60.0 \pm 14.1$ & .916 \\
Gender, male & $31(81.6 \%)$ & $971(69.0 \%)$ & .097 \\
Race, white & $36(100.0 \%)$ & $1191(90.0 \%)$ & .043 \\
Maximum aortic diameter & & & \\
$\quad$ Aortic annulus & $2.9(2.6-3.1)$ & $2.5(2.3-2.8)$ & .042 \\
$\quad$ Aortic root (sinus level) & $4.8(4.0-6.0)$ & $4.2(3.7-5.0)$ & .025 \\
$\quad$ Sinotubular junction & $4.5(3.9-5.4)$ & $4.0(3.4-4.6)$ & .080 \\
$\quad$ Ascending aorta & $5.0(4.3-5.6)$ & $5.0(4.5-5.7)$ & .557 \\
\hline POMI, Postoperative myocardial infarction. & &
\end{tabular}

dissection, preoperative MI, and old and new Q waves on EKG. A total of 1445 patients with surgically managed acute type A dissection were then examined, of whom 38 $(2.6 \%)$ had a POMI. Baseline characteristics and clinical presentation of patients with acute type A aortic dissection with and without POMI are shown in Tables 1 and 2. Patients with POMI were more likely to be Caucasian and to have a history of bicuspid aortic valve. Proximal extent of aortic dissection to the level of the aortic root was associated with a higher likelihood of POMI. Aortic annulus, aortic root, and sinotubular junction diameters were greater in patients with POMI. Preoperative imaging studies, consisting primarily of computed tomography angiography, were more likely to demonstrate pericardial effusion and coronary artery compromise in patients with POMI.

Operative details differed between groups and are shown in Tables 3 and 4. Hypotension or shock during surgery was associated with a higher incidence of POMI. Root replacement was associated with an increased risk of POMI $(4.4 \%$ vs $1.9 \%$ in patients not undergoing root replacement). Coronary artery bypass grafting was associated with an increased risk of POMI $(9.6 \%$ vs $2.1 \%$ in patients not undergoing coronary artery bypass grafting). Aortic valve replacement was associated with an increased risk of POMI ( $4.4 \%$ vs $2.1 \%$ in patients not undergoing aortic valve replacement). Longer circulatory arrest times were more frequent in patients with POMI, with a mean time of 60 minutes in those with POMI versus 38 minutes in those without POMI $(P=.024)$.

In-hospital outcomes are shown in Table 5. Patients with POMI had a higher rate of coma than patients without POMI $(17.1 \%$ vs $2.7 \%)$, as well as higher rates of mesenteric ischemia or infarction $(13.2 \%$ vs $2.3 \%)$, acute renal failure $(34.2 \%$ vs $16.6 \%)$, and postoperative hypotension $(23.7 \%$ vs $8.4 \%)$. In-hospital mortality was significantly higher in patients with POMI compared with those without POMI $(57.9 \%$ vs $16.3 \% ; P<.001)$.

Variables influencing mortality in type A dissection were examined in univariate analysis (Table 6). Next multivariate analysis was performed. Year of dissection was examined as a variable, dividing patients into 3 time groups: January 1996 to December 2001, January 2002 to December 2007, and January 2008 to December 2012. Presenting in the latest time period was inversely associated with in-hospital mortality, even after adjusting for POMI (Table 7). Other variables that proved significant in multivariable analysis included age and initial presentation with syncope (Table 7).

Intermediate-term survival by Kaplan-Meier analysis with confidence limits is shown in Figure 2. Log-rank

TABLE 3. Operative details

\begin{tabular}{|c|c|c|c|}
\hline Variable & $\begin{array}{c}\text { Frequency of POMI when variable } \\
\text { in first column present }\end{array}$ & $\begin{array}{c}\text { Frequency of POMI when variable } \\
\text { in first column absent }\end{array}$ & $P$ value \\
\hline \multicolumn{4}{|l|}{ Hemodynamics at surgery } \\
\hline Hypotensive/shock & $15 / 332(4.5 \%)$ & $23 / 1113(2.1 \%)$ & .021 \\
\hline Normotensive & $10 / 700(1.4 \%)$ & $28 / 745(3.8 \%)$ & .001 \\
\hline LV dysfunction & $4 / 88(4.5 \%)$ & $34 / 1357(2.5 \%)$ & .291 \\
\hline RV dysfunction & $3 / 63(4.8 \%)$ & $35 / 1382(2.5 \%)$ & .416 \\
\hline Lower-extremity ischemia & $0 / 73(0.0 \%)$ & $38 / 1372(2.8 \%)$ & .259 \\
\hline Root replacement & $18 / 408(4.4 \%)$ & $20 / 1037(1.9 \%)$ & .011 \\
\hline Ascending replacement & $34 / 1307(2.6 \%)$ & $4 / 134(3.0 \%)$ & .464 \\
\hline Partial arch replacement & $20 / 587(3.4 \%)$ & $18 / 858(2.1 \%)$ & .188 \\
\hline Complete arch replacement & $1 / 185(0.5 \%)$ & $37 / 1260(2.9 \%)$ & .050 \\
\hline Descending replacement & $1 / 36(2.8 \%)$ & $37 / 1409(2.6 \%)$ & 1.000 \\
\hline $\mathrm{CABG}$ & $10 / 104(9.6 \%)$ & $28 / 1341(2.1 \%)$ & $<.001$ \\
\hline MVR & $0 / 4(0.0 \%)$ & $38 / 1441(2.6 \%)$ & 1.000 \\
\hline AVR & $14 / 317(4.4 \%)$ & $24 / 1128(2.1 \%)$ & .027 \\
\hline Reoperation & $2 / 120(1.7 \%)$ & $36 / 1325(2.7 \%)$ & .764 \\
\hline Cerebral perfusion & $23 / 860(2.7 \%)$ & $15 / 585(2.6 \%)$ & .852 \\
\hline Hypothermic circulatory arrest & $34 / 1204(2.8 \%)$ & $4 / 241(1.7 \%)$ & .612 \\
\hline
\end{tabular}

POMI, Postoperative myocardial infarction; $L V$, left ventricle; $R V$, right ventricle; $C A B G$, coronary artery bypass grafting; $M V R$, mitral valve replacement; $A V R$, aortic valve replacement. 
TABLE 4. Operative details for continuous variables

\begin{tabular}{|c|c|c|c|}
\hline Variable & $\begin{array}{c}\text { POMI } \\
(\mathbf{n}=\mathbf{3 8})\end{array}$ & $\begin{array}{l}\text { No POMI } \\
(n=1407)\end{array}$ & $\begin{array}{c}P \\
\text { value }\end{array}$ \\
\hline Circulatory arrest time & $60.0(32.0-117.0)$ & $38.0(26.8-63.0)$ & .024 \\
\hline $\begin{array}{l}\text { CPB time, } \\
\text { median }(\mathrm{Q} 1-\mathrm{Q} 3)\end{array}$ & $235.0(208.5-369.0)$ & $188.5(150.0-234.0)$ & .006 \\
\hline $\begin{array}{l}\text { Crossclamp time } \\
\text { or cardiac arrest time, } \\
\text { median (Q1-Q3) }\end{array}$ & $155.0(59.5-188.0)$ & $105.0(70.8-136.0)$ & .186 \\
\hline
\end{tabular}

analysis revealed a significant reduction in the survival of patients with POMI compared with those without POMI $(P=.007)$. Freedom from reoperation did not differ between those with POMI and those without POMI $(P=.75)$.

\section{DISCUSSION}

MI may be a presenting feature of acute type A aortic dissection. With aortic dissection, the intimal flap may propagate into the coronary arteries, causing MI. ${ }^{8,9}$ Preoperative MI occurs in $1 \%$ to $7 \%$ of all patients presenting with type A aortic dissection. ${ }^{9}$ MI was seen in $5 \%$ of patients in a study from the IRAD database. ${ }^{10}$ It has also been reported that preoperative MI is a risk factor for mortality in type A dissection. ${ }^{11,12}$ For example, Chirillo and colleagues conducted a retrospective review of 290 patients with acute type A aortic dissection and found that preoperative MI was a significant predictor of operative mortality. ${ }^{12}$

However, less is known about patients who develop a new POMI after repair of acute type A aortic dissection. A previous report from the IRAD database suggested that myocardial ischemia may be a risk factor for mortality in type A dissection, ${ }^{13}$ but this report grouped together patients with preoperative MI and POMI. We sought to define outcomes after POMI in patients undergoing surgical repair for acute type $\mathrm{A}$ dissection and to identify

TABLE 5. Postoperative complications

\begin{tabular}{lccr}
\hline \multicolumn{1}{c}{ Variable } & $\begin{array}{c}\text { POMI } \\
(\mathbf{n = 3 8})\end{array}$ & $\begin{array}{r}\text { No POMI } \\
(\mathbf{n = 1 4 0 7 )}\end{array}$ & $\begin{array}{c}\boldsymbol{P} \\
\text { value }\end{array}$ \\
\hline New neurologic deficit & & & \\
$\quad$ CVA & $2(5.7 \%)$ & $100(8.1 \%)$ & 1.000 \\
Coma & $6(17.1 \%)$ & $33(2.7 \%)$ & $<.001$ \\
$\quad$ Spinal cord ischemia & $0(0.0 \%)$ & $22(1.8 \%)$ & 1.000 \\
Mesenteric ischemia/infarction & $5(13.2 \%)$ & $32(2.3 \%)$ & .002 \\
Acute renal failure & $13(34.2 \%)$ & $232(16.6 \%)$ & .004 \\
Extension of dissection & $1(2.6 \%)$ & $24(1.7 \%)$ & .491 \\
Hypotension & $9(23.7 \%)$ & $117(8.4 \%)$ & .004 \\
Cardiac tamponade & $3(7.9 \%)$ & $59(4.2 \%)$ & .223 \\
Limb ischemia & $1(2.6 \%)$ & $23(1.6 \%)$ & .477 \\
In-hospital mortality & $22(57.9 \%)$ & $229(16.3 \%)$ & $<.001$ \\
\hline POMI, Postopetive myon
\end{tabular}

POMI, Postoperative myocardial infarction; $C V A$, cerebrovascular accident.
TABLE 6. Univariate analysis of in-hospital mortality after type A dissection

\begin{tabular}{|c|c|c|}
\hline Variable & OR & $P$ value \\
\hline POMI & 7.07 & $<.001$ \\
\hline Atherosclerosis & 1.47 & .057 \\
\hline Known aortic aneurysm & 1.90 & .002 \\
\hline Chronic obstructive pulmonary disease & 2.49 & .027 \\
\hline Prior aortic valve replacement & 1.96 & .038 \\
\hline Presenting chest pain & 0.63 & .009 \\
\hline Presenting chest pain - anterior & 0.62 & .011 \\
\hline Mild pain at presentation & 0.54 & .105 \\
\hline Presenting head or neck pain & 0.74 & .077 \\
\hline Radiating pain at presentation & 0.719 & .036 \\
\hline Migrating pain at presentation & 1.40 & .071 \\
\hline Presenting leg pain & 1.47 & .057 \\
\hline Presenting normotension & 0.53 & $<.001$ \\
\hline Normal findings on presenting chest $\mathrm{x}$-ray & 0.61 & .021 \\
\hline Presenting syncope & 1.67 & .003 \\
\hline Presenting hypotension & 1.55 & .014 \\
\hline Any pulse deficit on presentation & 1.67 & .002 \\
\hline Beta-blocker administered on presentation & 0.51 & $<.001$ \\
\hline Calcium channel blocker administered on presentation & 0.50 & .017 \\
\hline Nitroprusside administered on presentation & 0.71 & .058 \\
\hline Vasopressor administered on arrival & 2.93 & $<.001$ \\
\hline Intramural hematoma on imaging & 0.73 & .113 \\
\hline Site of intimal tear - multiple & 1.82 & .188 \\
\hline Abdominal vessel involvement on imaging & 1.27 & .156 \\
\hline Periaortic hematoma & 1.43 & .036 \\
\hline Age $\geq 70$ y & 1.89 & $<.001$ \\
\hline Age* & 1.03 & $<.001$ \\
\hline
\end{tabular}

$O R$, Odds ratio; $P O M I$, postoperative myocardial infarction. *Age was introduced as a continuous variable.

preoperative risk factors for this complication. In this large cohort of patients from the IRAD database, we demonstrated that new POMI is associated with a significantly increased mortality rate, with $57.9 \%$ of patients experiencing in-hospital mortality compared with $16.3 \%$ of patients who did not develop a POMI.

As one would expect, the extent of operative repair for acute type A aortic dissection is associated with POMI. Patients requiring root replacement and thereby coronary

TABLE 7. Multivariable analysis of in-hospital mortality after type A dissection

\begin{tabular}{lccr}
\hline \multicolumn{1}{c}{ Variable } & OR & $\mathbf{9 5} \%$ CI for OR & $\boldsymbol{P}$ value \\
\hline POMI & 5.13 & $2.09-12.62$ & $<.001$ \\
Age* & 1.04 & $1.03-1.06$ & $<.001$ \\
Presenting head/neck pain & 0.62 & $0.41-0.95$ & .028 \\
Presenting syncope & 1.76 & $1.14-2.71$ & .011 \\
Presenting normotensive & 0.49 & $0.33-0.71$ & $<.001$ \\
Any pulse deficit & 1.83 & $1.27-2.65$ & .001 \\
Dissection 2002-2007 & 0.73 & $0.49-1.08$ & .112 \\
Dissection 2008-2012 & 0.45 & $0.28-0.72$ & .001 \\
\hline$O R$, Odd
\end{tabular}

$O R$, Odds ratio; $C I$, confidence interval; $P O M I$, postoperative myocardial infarction. *Age was introduced as a continuous variable. 


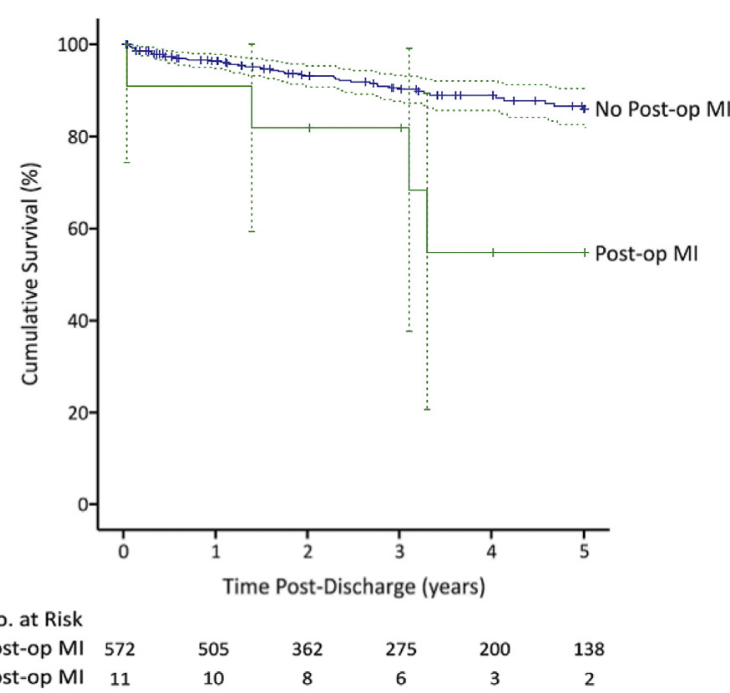

FIGURE 2. Survival after repair of acute type A dissection. MI, Myocardial infarction.

reimplantation, coronary artery bypass grafting, or aortic valve replacement are at higher risk for POMI. Preoperative imaging revealing more proximal aortic involvement also identifies a cohort of patients with increased risk for POMI. Dissection within the aortic root conferred increased risk, with a greater fraction of patients with POMI having dissection in the aortic root (sinuses of Valsalva) on preoperative imaging. Few patients underwent preoperative angiography, and proximal aortic involvement including coronary involvement was detected largely by computed tomography angiography.

Aortic annulus, aortic root, and sinotubular junction diameters were greater in patients with POMI, and these patients were more likely to have a pericardial effusion and coronary artery compromise on preoperative imaging. Larger aortic diameters signify preexisting aneurysmal dilatation of aortic root or annuloaortic ectasia. These patients typically will require more extensive "proximal operation," such as Bentall, David, Yacoub, or Cabrol operations. ${ }^{14,15}$ These 4 procedures include left and right coronary implantation, thereby having higher risk for coronary mishaps causing POMI compared with patients undergoing supracoronary Dacron graft implantation or a Wheat operation. ${ }^{16}$

Of note, the presence of a bicuspid aortic valve also was found to be a risk factor for MI. Bicuspid aortic valve has been associated with an increased ratio of proximal aortic aneurysm and aortic dissection. ${ }^{17,18}$ Therefore, patients with bicuspid aortic valve and acute type A dissection will often require a root replacement similar to patients with bicuspid aortic valve who require elective root replacement for root aneurysm ${ }^{19,20}$ and will be at higher risk for POMI for the aforementioned reasons.
The current study expands on a previous report from the IRAD database examining the effect of root replacement versus conservative root management in type A dissection. $^{21}$ That study demonstrated that patients undergoing root replacement were younger, presented with larger root diameter, and were more likely to have bicuspid valves, Marfan syndrome, or aortic insufficiency. Root replacement did not increase hospital mortality, although there was an increased incidence of POMI in the group undergoing root replacement. That report was not designed to examine outcomes in the relatively small subset of patients having a POMI. It also did not examine all patients with POMI after repair of a type A dissection, regardless of whether a root replacement was performed or not. The present study looks specifically at patients with POMI and demonstrates that POMI, regardless of extent of aortic replacement, is a marker for adverse outcomes. It is noteworthy that patients with POMI had longer circulatory arrest times, but approximately the same percentage underwent hemiarch or total arch replacement. Although it may be that longer circulatory arrest time contributed to less optimal myocardial protection in this group, other factors such as root replacement and proximal aortic size still emerge as risk factors for POMI in multivariate analysis.

POMI was associated with increased end-organ complications, including coma, mesenteric ischemia, and acute renal failure. Whether these complications are the result of POMI and low-cardiac output remains to be clarified by future studies. In particular, whether such complications arise as a result of a malperfusion syndrome, rather than due to POMI, remains an area for future study. Finally, patients who do survive to discharge after a POMI have a lower rate of 5-year survival, although reoperation rates are similar.

\section{Study Limitations}

There are several limitations to this study. First, the data are collected both retrospectively and prospectively, and the potential exists for reporting bias. Second, the data from the IRAD are limited on details about timing of the POMIs, and not all patients had data reported for all variables. In particular, it is possible that some preoperative MIs were missed because of the urgency of operative management. Third, the classic difficulty in distinguishing poor myocardial protection from POMI remains, and we have chosen to use common cutoffs in the literature for creatine kinase-MB and troponin thresholds. Fourth, the specific reasons for a patient undergoing coronary artery bypass grafting in addition to type A dissection repair are not captured by the current database. Although we speculate that these patients had coronary artery compromise by dissection or known significant ungrafted coronary disease, this is not specifically coded as an entry variable in the current database. Finally, the limited number of patients remaining in the POMI group past 1 year makes it difficult 
to draw firm conclusions regarding intermediate-term risk in this cohort of patients. Despite these limitations, this study provides unique information from a large international and multicenter registry.

\section{CONCLUSIONS}

Future studies will help to further elucidate the cause of POMI. In particular, POMI may be a correlate of extensive dissection and unrelated to prior coronary artery disease. Next, the optimal management of POMI remains to be elucidated. Whether patients with POMI have reduced cardiac output and whether this can be modified to improve outcomes are topics for future research. Finally, whether the operative intervention can be modified to reduce the risk of POMI in patients with proximal dissection remains uncertain.

\section{Conflict of Interest Statement}

Authors have nothing to disclose with regard to commercial support.

\section{References}

1. Clouse WD, Hallett JW Jr, Schaff HV, Spittell PC, Rowland CM, Ilstrup DM, et al. Acute aortic dissection: population-based incidence compared with degenerative aortic aneurysm rupture. Mayo Clin Proc. 2004;79:176-80.

2. Hagan PG, Nienaber CA, Isselbacher EM, Bruckman D, Karavite DJ, Russman PL, et al. The International Registry of Acute Aortic Dissection (IRAD): new insights into an old disease. JAMA. 2000;283:897-903.

3. Ramsay J, Shernan S, Fitch J, Finnegan P, Todaro T, Filloon T, et al. Increased creatine kinase MB levels predict postoperative mortality after cardiac surgery independent of new Q waves. J Thorac Cardiovasc Surg. 2005;129:300-6.

4. Klatte K, Chaitman BR, Theroux P, Gavard JA, Stocke K, Boyce S, et al. Increased mortality after coronary artery bypass graft surgery is associated with increased levels of postoperative creatine-kinase myocardial band isoenzyme release. J Am Coll Cardiol. 2001;38:1070-7.

5. Mohammed AA, Agnihotri AK, van Kimmenade RR, Martinez-Rumayor A, Green SM, Quiroz R, et al. Prospective, comprehensive assessment of cardiac troponin $\mathrm{T}$ testing after coronary artery bypass graft surgery. Circulation. 2009; 120:843-50.
6. Yau JM, Alexander JH, Hafley G, Mahaffey KW, Mack MJ, Kouchoukos N, et al. Impact of perioperative myocardial infarction on angiographic and clinical outcomes following coronary artery bypass grafting (from project of ex-vivo vein graft engineering via transfection [PREVENT] IV). Am J Cardiol. 2008; 102:546-51.

7. Daily PO, Trueblood HW, Stinson EB, Wuerflein RD, Shumway NE Management of acute aortic dissections. Ann Thorac Surg. 1970;10:237-47.

8. D’Aloia A, Vizzardi E, Bugatti S, Magatelli M, Bonadei I, Rovetta R, et al. A type A aortic dissection mimicking an acute myocardial infarction. Cardiol Res. 2012;3:94-6.

9. Braverman AC. Aortic dissection: prompt diagnosis and emergency treatment are critical. Cleve Clin J Med. 2011;78:685-96.

10. Eagle KA, Isselbacher EM, DeSanctis RW. Cocaine-related aortic dissection in perspective. Circulation. 2002;105:1529-30.

11. Kawada T, Okada Y, Aiba M, Sekiguchi S, Yamada M, Michihata T, et al Changing predictors of postoperative mortality in acute type A aortic dissection. Is only coronary artery compromise significant? Jpn J Thorac Cardiovasc Surg. 2001;49:347-54.

12. Chirillo F, Marchiori MC, Andriolo L, Razzolini R, Mazzucco A, Gallucci V, et al. Outcome of 290 patients with aortic dissection. A 12-year multicentre experience. Eur Heart J. 1990;11:311-9.

13. Mehta RH, Suzuki T, Hagan PG, Bossone E, Gilon D, Llovet A, et al. Predicting death in patients with acute type A aortic dissection. Circulation. 2002;105: 200-6.

14. Yacoub MH, Gehle P, Chandrasekaran V, Birks EJ, Child A, Radley-Smith R. Late results of a valve-preserving operation in patients with aneurysms of the ascending aorta and root. J Thorac Cardiovasc Surg. 1998;115:1080-90.

15. David TE, Armstrong S, Ivanov J, Feindel CM, Omran A, Webb G. Results of aortic valve-sparing operations. J Thorac Cardiovasc Surg. 2001;122:39-46.

16. Wheat MW Jr, Wilson JR, Bartley TD. Successful replacement of the entire ascending aorta and aortic valve. JAMA. 1964;188:717-9.

17. Edwards WD, Leaf DS, Edwards JE. Dissecting aortic aneurysm associated with congenital bicuspid aortic valve. Circulation. 1978;57:1022-5.

18. Roberts CS, Roberts WC. Dissection of the aorta associated with congenital malformation of the aortic valve. J Am Coll Cardiol. 1991;17:712-6.

19. Schafers HJ, Kunihara T, Fries P, Brittner B, Aicher D. Valve-preserving roo replacement in bicuspid aortic valves. J Thorac Cardiovasc Surg. 2010;140(6 Suppl):S36-40.

20. Ando M, Okita Y, Morota T, Takamoto S. Thoracic aortic aneurysm associated with congenital bicuspid aortic valve. Cardiovasc Surg. 1998;6:629-34.

21. Di Eusanio M, Trimarchi S, Peterson MD, Myrmel T, Hughes GC, Korach A et al. Root replacement surgery versus more conservative management during type A acute aortic dissection repair. Ann Thorac Surg. 2014;98:2078-85.

Key Words: aortic dissection, type A dissection, myocardial infarction 